\title{
NOTE \\ Virology \\ Simple and rapid method for routine screening of bovine leukemia virus by loop- mediated isothermal amplification assay
}

\author{
Yuka OKUWA ${ }^{1)}$, Michiko MIYAMATO-HAYASHI ${ }^{2}$, Takaichi TANAKA ${ }^{1)}$, \\ Yuji HAYAKAWA ${ }^{1)}$ and Yasuo INOSHIMA ${ }^{3,4) *}$ \\ 1) Nanbu Livestock Hygiene Service Center, 324-2 Bo, Saida-machi, Kanazawa, Ishikawa 920-3101, Japan \\ 2)Ishikawa Agriculture and Forestry Research Center, Livestock Experiment Station, 93-2 Na, Tsuboyama, \\ Houdatsushimizu, Hakui, Ishikawa 929-1325, Japan \\ 3) Laboratory of Food and Environmental Hygiene, Cooperative Department of Veterinary Medicine, Gifu \\ University, 1-1 Yanagido, Gifu 501-1193, Japan \\ 4)The United Graduate School of Veterinary Sciences, Gifu University, 1-1 Yanagido, Gifu 501-1193, Japan
}

J. Vet. Med. Sci.

79(1): 137-140, 2017

doi: $10.1292 / j v m s .16-0328$

Received: 21 June 2016

Accepted: 21 September 2016

Published online in J-STAGE:

3 October 2016
ABSTRACT. Various techniques for screening and detection of bovine leukemia virus (BLV) were compared to ascertain a rapid and simple technique for routine examination. The performance of real-time PCR, nested PCR and loop-mediated isothermal amplification (LAMP) assays was compared using DNA extracted from whole blood instead of white blood cells (WBCs) of 23 cattle. Real-time PCR, LAMP and nested PCR detected 18, 16 and 11 BLV-positive cattle, respectively. These results suggest that LAMP using DNA from whole blood could enable rapid examination, as isolation of WBCs and electrophoresis is time-consuming and could be useful as a simple and rapid method for routine screening of BLV.

KEY WORDS: blood DNA, bovine leukemia virus, cattle, loop-mediated isothermal amplification, screening

Bovine leukemia virus (BLV) is the etiological agent of enzootic bovine leukosis [7]. BLV infects circulating B cells and induces malignant leukosis in cattle [16]. The majority of cattle infected with BLV are sub-clinical carriers of the virus, and about $30 \%$ of BLV-infected cattle develop persistent lymphocytosis without clinical signs [7].

BLV infection has been reported globally and is prevalent in Japan [2, 11]. According to a recent nationwide survey in Japan, BLV is spreading widely among dairy cattle, where BLV seroprevalence from 2009 to 2011 (40.9\%) [11] was approximately 10-fold higher than that reported in 1980 (3.7\%) [1]. It is thought that sub-clinical carriers of BLV become the source of infection and further spread of the disease. BLV-infected herds without clinical signs show decreased milk production and increased risk of suffering from an infectious disease [3]. Thus, if cattle are infected with BLV, selection and restrictions are imposed on the commerce; the economic loss due to BLV infection is thus immense. Therefore, it is important to diagnose BLV infection accurately in order to eradicate it.

There are various techniques for diagnosis of BLV infection. The syncytia induction assay and the polymerase chain reaction (PCR) have been used for detection of BLV antigen and BLV DNA, and indirect hemagglutination (IHA), enzyme-linked immunosorbent assay (ELISA), radioimmunoassay, indirect fluorescent antibody test and syncytium inhibition test have been used for detection of antibody against BLV, respectively $[1,6,7,9]$. These serological tests and removal of seropositive cattle from farms will enable the reduction in the number of BLV-infected cattle significantly, but these tests are not adequate to identify cattle during the early stages of infection when the antibody is not yet induced [5]. Since BLV infection is chronic and persistent, it is important to detect BLV DNA as well as antibody. Proviral BLV DNA is found in isolated white blood cells (WBCs) [16], and it can be detected by PCR $[4,12]$. However, single PCR does not have sufficient sensitivity, and thus, it is essential to use nested PCR $[4,12]$. Nested PCR is time-consuming, and there is a high risk of DNA cross-contamination from the first PCR. Although real-time PCR is much more specific and sensitive than nested PCR, it is an expensive technique and requires special facility and equipment.

Therefore, in this study, to shorten time for a routine examination and reduce laborious efforts, a simple and rapid screening procedure was evaluated for detection of BLV infection by using DNA extracted from whole blood instead of WBCs and loopmediated isothermal amplification (LAMP) as a DNA amplification method.

*Correspondence to: Inoshima, Y., Laboratory of Food and Environmental Hygiene, Department of Veterinary Medicine, Gifu University, 1-1 Yanagido, Gifu 501-1193, Japan. e-mail: inoshima@gifu-u.ac.jp

O2017 The Japanese Society of Veterinary Science

This is an open-access article distributed under the terms of the Creative Commons Attribution Non-Commercial No Derivatives (by-ncnd) License <http://creativecommons.org/licenses/by-nc-nd/4.0/>. 
Blood was collected from 23 Holstein cattle in Ishikawa prefecture in 2015. Four to five milliliters of blood were treated with ethylenediaminetetraacetic acid (EDTA), and WBC was isolated by hemolysis with $0.83 \%$ ammonium chloride followed by washing twice with phosphate buffered saline (PBS). DNA was extracted both from EDTA-treated whole blood (200 $\mu l)$ and WBCs by using a QIAamp DNA Mini Kit (Qiagen, Tokyo, Japan) according to the manufacturer's instructions, and the extracted DNA was used as blood DNA and WBC DNA, respectively. Plasma samples were also obtained from the same cattle.

After measurement of DNA concentration of WBC DNA by a spectrophotometer UV-1700 (SHIMADZU, Kyoto, Japan), DNA concentration was adjusted to $20 \mathrm{ng} / \mu l$ and $5 \mu l$ was used for real-time PCR detecting BLV Tax gene using a commercially available Cycleave PCR BLV detection kit (TaKaRa Bio, Otsu, Japan) according to the manufacturer's instructions. The BLV copy numbers per $10 \mathrm{ng}$ were determined.

Primers to amplify the envelope or pX region of BLV were used for nested PCR, according to the protocols by Fechner et al. [4] and Murakami et al. [12]. PCR was carried out in a total reaction volume of $25 \mu l$ containing 0.625 U of TAKARA Ex Taq (TaKaRa Bio), $0.4 \mu \mathrm{mol} / l$ of forward and reverse primers, and $2 \mu l$ of extracted blood DNA or WBC DNA. PCR products were electrophoresed on 2\% agarose gel in Tris acetate EDTA (TAE) buffer, stained with ethidium bromide and visualized under a UV illuminator.

LAMP assay was carried out using primers specific to the LTR region of BLV DNA as described previously [8] with the Loopamp DNA amplification kit (Eiken Chemical, Tochigi, Japan). The $25 \mu l$ reaction mixture contained $40 \mathrm{pmol} / 25 \mu l$ of each inner primer (FIP, BIP), 5 pmol/25 $\mu l$ of each outer primer (F3, B3), 20 pmol/25 $\mu l$ of each loop primer (FLP, BLP), $1 \times$ reaction mixture, $8 \mathrm{U}$ of Bst DNA polymerase and $5 \mu l$ of extracted blood DNA or WBC DNA from each sample. In the LAMP reaction mixture, $1 \mu l$ of Fluorescent Detection Reagent (Eiken Chemical) was added according to the manufacturer's instructions to facilitate visual detection. The mixtures were incubated at $63^{\circ} \mathrm{C}$ for $1 \mathrm{hr}$ and then heated at $80^{\circ} \mathrm{C}$ for 5 min to terminate the reaction in a Loopamp EXIA real-time turbidimeter (Teramecs, Kyoto, Japan). The amplification of DNA was also confirmed by the detection of fluorescence visualized in a UV illuminator.

An anti-BLV antibody ELISA kit (JNC Inc., Tokyo, Japan) was used to detect anti-BLV antibodies according to the manufacturer's instructions.

First, real-time PCR was carried out for detection of BLV DNA and measurement of BLV copy number using DNA extracted from the WBCs of 23 cattle. Five samples were negative, and 18 were positive for BLV DNA. The copy numbers of positive samples detected by real-time PCR were in the range of $0.3-360$ copies/10 $\mathrm{ng}$ DNA. The same number of positive results was obtained by nested PCR. Among these 18 positive samples by real-time PCR, BLV DNA was not amplified from one sample in the LAMP assay (Fig. 1). The copy number of this sample was 0.3 copies/10 $\mathrm{ng}$ DNA. Whereas, five negative samples detected by real-time PCR were also detected to be negative by both nested PCR and LAMP assays.

Further, to shorten time and reduce efforts for isolation of WBCs from whole blood, the sensitivity of nested PCR and LAMP assays was evaluated using blood DNA. The number of positive samples detected by real-time PCR of blood DNA was the same as that detected by real-time PCR of WBC DNA, i.e., 18 blood DNA samples were positive for BLV DNA (data not shown). Among these 18 positive samples, 16 samples were found to be positive, but 2 samples were found to be negative by the LAMP assay (Fig. 1). In contrast, 11 of 18 samples were found to be positive, but seven samples were found to be negative by the nested PCR (Fig. 1). BLV copy numbers of the seven negative samples were detected by nested PCR, and they ranged widely from 0.3 to 215 copies/10 $\mathrm{ng}$ DNA, whereas those of the two negative samples detected by LAMP assay were less than $1 \mathrm{copy} / 10 \mathrm{ng}$ DNA (0.3 and 0.4 copies/10 ng DNA) (Table 1). These results were confirmed by repeated experiments. As for negative results by nested PCR, but positive results by real-time PCR, we think a possibility that different numbers of WBCs in $200 \mu l$ of whole blood in each sample caused this discrepancy. In the negative samples by nested PCR, but positive by real-time PCR, the number of WBCs was significantly lower than the positive samples $(P<0.1)$, resulting in lower DNA concentration (data not shown). The LAMP assay has a characteristic feature of being more sensitive than PCR $[8,13]$. In this study, LAMP assay was more sensitive than nested PCR in blood DNA. Moreover, real-time PCR, nested PCR and LAMP assays can be performed within 1.5, 4 and 1 hr, respectively. These results revealed that LAMP assay using blood DNA could be more suitable for simple and rapid screening of BLV than nested PCR.

ELISA measured antibody against BLV in 23 cattle. The results showed 18 out of the 23 samples to be positive for antibody, which was almost consistent with the number of positive results of BLV DNA detected by real-time PCR (Table 1). Among these 18 ELISA antibody-positive samples, one sample was found to be negative for BLV DNA by the real-time PCR, nested PCR and LAMP assays. This sample might be positive for BLV antibody due to the presence of maternal antibody as the sample was obtained from 1-month-old cattle. Conversely, one out of the five BLV antibody-negative samples was found to be positive for BLV DNA by real-time PCR, nested PCR and LAMP assays using WBC DNA. However, three weeks later, this sample became positive for the antibody, suggesting that real-time PCR, nested PCR and LAMP assays can diagnose cattle in the early stage of BLV infection where antibody was not yet induced; this is in accordance with a previous report [8]. To prevent missing out of cattle in the early stage of BLV infection, both genetic screening and serological examinations should be carried out.

In conclusion, our results suggest that LAMP assay using blood DNA could be more suitable for simple and rapid screening of BLV. Real-time PCR is the most sensitive method as compared to other methods used in this study. It can detect BLV infection even in the early stages when anti-BLV antibody is not yet induced and can measure the viral copy numbers [15]. However, it is unsuitable for screening of BLV, because the analysis cost per sample is high. Nested PCR is cheaper than real-time PCR, but it requires longer time and has a high risk of DNA cross-contamination, causing misdiagnosis. The time required for LAMP assay is shorter than that required for nested PCR, and it could reduce a contamination risk because it does not require a downstream 


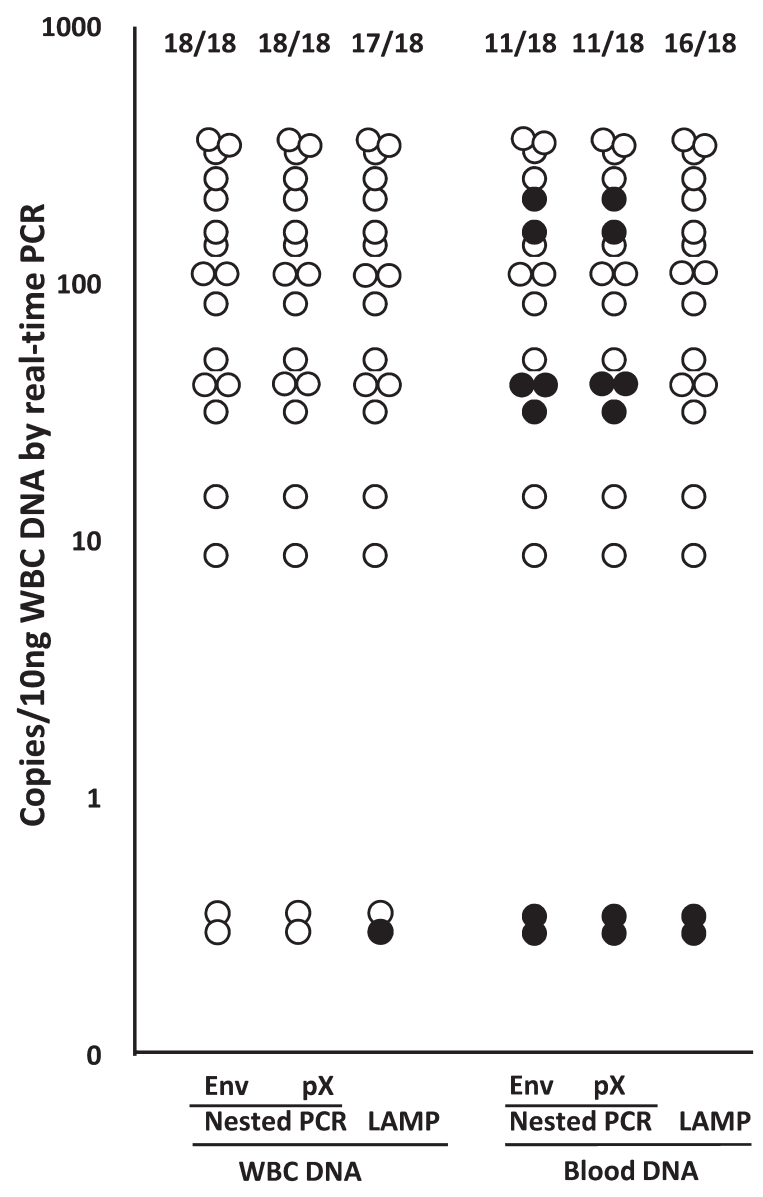

Fig. 1. Comparison of detectability of BLV among real-time PCR, nested PCR and LAMP assays using WBC DNA or blood DNA. $\circ$, positive by nested PCR or LAMP assay. $\bullet$, negative by nested PCR or LAMP assay. The numbers of the top indicate the numbers of positive samples/18 positive samples by real-time PCR using WBC DNA.

analysis like electrophoresis and it can be detected visually, leading to a rapid analysis. BLV-infected cattle carrying high viral copy numbers could be a high risk factor in farms as a source of spreading the infection [10, 14]. LAMP assay could not detect the samples having less than 1 copy/10 $\mathrm{ng}$ DNA, and the sensitivity would be enough for screening because the risk of spreading BLV infection from these cattle is presumably lower than that from cattle having high copy numbers. LAMP assay can be performed only with a water bath or a heating block for maintaining isothermal conditions [13], which are available in facilities where special machines and laboratory equipment, such as a thermal cycler, are unavailable. Therefore, combination LAMP assay with blood DNA could be suitable for the inspection of many samples, including the routine screening of BLV.

ACKNOWLEDGMENTS. This study was supported in part by a Grant-in-Aid (No. 16H05027) for Scientific Research from the Ministry of Education, Culture, Sports, Science and Technology, Japan. This study was also supported in part by the Kieikai Research Foundation, the Ogaki Kyoritsu Bank and the Center for Collaborative Study with Community, Gifu University.

\section{REFERENCES}

1. Agriculture, Forestry and Fisheries Research Council. 1986. Research Accomplishment Report No. 174. Ministry of Agriculture, Forestry and Fishery, Japan (in Japanese)

2. Asfaw, Y., Tsuduku, S., Konishi, M., Murakami, K., Tsuboi, T., Wu, D. and Sentsui, H. 2005. Distribution and superinfection of bovine leukemia virus genotypes in Japan. Arch. Virol. 150: 493-505. [Medline] [CrossRef]

3. Emanuelson, U., Scherling, K. and Pettersson, H. 1992. Relationships between herd bovine leukemia virus infection status and reproduction, disease incidence, and productivity in Swedish dairy herds. Prev. Vet. Med. 12: 121-131. [CrossRef]

4. Fechner, H., Blankenstein, P., Looman, A. C., Elwert, J., Geue, L., Albrecht, C., Kurg, A., Beier, D., Marquardt, O. and Ebner, D. 1997. Provirus variants of the bovine leukemia virus and their relation to the serological status of naturally infected cattle. Virology 237: 261-269. [Medline] [CrossRef]

5. Jacobs, R. M., Song, Z., Poon, H., Heeney, J. L., Taylor, J. A., Jefferson, B., Vernau, W. and Valli, V. E. 1992. Proviral detection and serology in bovine leukemia virus-exposed normal cattle and cattle with lymphoma. Can. J. Vet. Res. 56: 339-348. [Medline]

6. Hoff-Jørgensen, R. 1989. An international comparison of different laboratory tests for the diagnosis of bovine leukosis: suggestions for international 
Table 1. Relation of age and quantitative proviral load to the qualitative results of nested PCR and LAMP assay, and anti-BLV antibody

\begin{tabular}{|c|c|c|c|c|c|c|}
\hline \multirow{3}{*}{$\begin{array}{c}\text { Cattle } \\
\text { No. }\end{array}$} & \multirow{3}{*}{$\begin{array}{c}\text { Age } \\
\text { (Month) }\end{array}$} & \multirow{3}{*}{$\begin{array}{c}\text { WBC DNA } \\
\text { Real-time PCR } \\
\text { (Copies/10 ng DNA) }\end{array}$} & \multicolumn{3}{|c|}{ Blood DNA } & \multirow{3}{*}{ Antibody } \\
\hline & & & \multicolumn{2}{|c|}{ Nested PCR } & \multirow{2}{*}{ LAMP } & \\
\hline & & & Envelope & $\mathrm{pX}$ & & \\
\hline 1 & 1 & - & - & - & - & + \\
\hline 2 & 27 & - & - & - & - & - \\
\hline 3 & 4 & - & - & - & - & - \\
\hline 4 & 1 & - & - & - & - & - \\
\hline 5 & 7 & - & - & - & - & - \\
\hline 6 & 68 & 0.3 & - & - & - & + \\
\hline 7 & 53 & 0.4 & - & - & - & + \\
\hline 8 & 46 & 9 & + & + & + & + \\
\hline 9 & 5 & 15 & + & + & + & + \\
\hline 10 & 54 & 32 & - & - & + & + \\
\hline 11 & 53 & 40 & - & - & + & + \\
\hline 12 & 52 & 40 & - & - & + & - \\
\hline 13 & 89 & 51 & + & + & + & + \\
\hline 14 & 8 & 84 & + & + & + & + \\
\hline 15 & 32 & 111 & + & + & + & + \\
\hline 16 & 82 & 114 & + & + & + & + \\
\hline 17 & 36 & 143 & + & + & + & + \\
\hline 18 & 27 & 160 & - & - & + & + \\
\hline 19 & 44 & 215 & - & - & + & + \\
\hline 20 & 32 & 258 & + & + & + & + \\
\hline 21 & 52 & 346 & + & + & + & + \\
\hline 22 & 57 & 350 & + & + & + & + \\
\hline 23 & 34 & 360 & + & + & + & + \\
\hline
\end{tabular}

standardization. Vet. Immunol. Immunopathol. 22: 293-297. [Medline] [CrossRef]

7. Kettmann, R., Burny, A., Callebaut, I., Droogmans, L., Mammerickx, M., Willems, L. and Portetelle, D. 1994. Bovine leukemia virus. pp. $39-81$. In: The Retroviridae, vol. 3. (Levy, J. A. ed.), Plenum Press, New York.

8. Komiyama, C., Suzuki, K., Miura, Y. and Sentsui, H. 2009. Development of loop-mediated isothermal amplification method for diagnosis of bovine leukemia virus infection. J. Virol. Methods 157: 175-179. [Medline] [CrossRef]

9. Kono, Y., Irishio, W. and Sentsui, H. 1983. Syncytium-induction inhibition test with complement for detection of antibodies against bovine leukemia virus. Can. J. Comp. Med. 47: 328-331. [Medline]

10. Murakami, K. 2009. Enzootic bovine leukosis (EBL) and recent prevalation and control measurement in Japan. Yamaguchi J. Vet. Med. 36: 5-30 (in Japanese).

11. Murakami, K., Kobayashi, S., Konishi, M., Kameyama, K. and Tsutsui, T. 2013. Nationwide survey of bovine leukemia virus infection among dairy and beef breeding cattle in Japan from 2009-2011. J. Vet. Med. Sci. 75: 1123-1126. [Medline] [CrossRef]

12. Murakami, K., Okada, K., Ikawa, Y. and Aida, Y. 1994. Bovine leukemia virus induces CD5- B cell lymphoma in sheep despite temporarily increasing $\mathrm{CD}^{+} \mathrm{B}$ cells in asymptomatic stage. Virology 202: 458-465. [Medline] [CrossRef]

13. Notomi, T., Okayama, H., Masubuchi, H., Yonekawa, T., Watanabe, K., Amino, N. and Hase, T. 2000. Loop-mediated isothermal amplification of DNA. Nucleic Acids Res. 28: e63. [Medline] [CrossRef]

14. Ohno, A., Takeshima, S. N., Matsumoto, Y. and Aida, Y. 2015. Risk factors associated with increased bovine leukemia virus proviral load in infected cattle in Japan from 2012 to 2014. Virus Res. 210: 283-290. [Medline] [CrossRef]

15. Sohmura, Y., Akase, S., Kurono, H. and Murakami, K. 2007. Application of real-time PCR for diagnosing enzootic bovine leukosis (EBL) on meat inspection. J. Vet. Med. 60: 1005-1012 (in Japanese).

16. Tajima, S., Ikawa, Y. and Aida, Y. 1998. Complete bovine leukemia virus (BLV) provirus is conserved in BLV-infected cattle throughout the course of B-cell lymphosarcoma development. J. Virol. 72: 7569-7576. [Medline] 